\title{
Differences in actin expression between primary and recurrent facial basal cell carcinomas as a prognostic factor of local recurrence
}

\author{
Katarzyna Iwulska ${ }^{1}$, Grażyna Wyszyńska-Pawelec ${ }^{1}$, Jan Zapała ${ }^{1}, B$ Bogdan Kosowski ${ }^{2 \dagger}$
}

${ }^{1}$ Department of Cranio-Maxillofacial, Oncological and Reconstructive Surgery, Jagiellonian University Medical College, Krakow, Poland ${ }^{2}$ Department of Pathology, Prosmed, Krakow, Poland

Adv Dermatol Allergol 2021; XXXVIII (3): 490-497

DOI: https://doi.org/10.5114/ada.2021.107935

\begin{abstract}
Introduction: Due to a relatively high recurrence rate of facial basal cell carcinoma (BCC), its morbidity is very significant.

Aim: To analyse the expression of $\alpha$-SMA, E-cadherin, Ber-Ep4 and MOC-31 as predictors of local recurrence in a group of patients with primary and recurrent BCCs of the face in correlation with histological and clinical data. Material and methods: The study cohort included 79 patients with facial BCC (52 with primary BCC and 27 with recurrent BCC) who were treated at the Department of Cranio-Maxillofacial Surgery of the Jagiellonian University, Krakow in 1997-2009.

Results: Significant risk factors for local recurrence included: recurrent tumour $(p=0.001)$, multifocal BCC $(p=0.01)$, incomplete tumour excision ( $p=0.02)$ and the aggressive infiltrating histologic subtype of BCC $(p=0.05)$. In the group of primary BCCs, positive expression of stromal $\alpha$-SMA $(p=0.03)$ correlated with a statistically significant higher recurrence rate and so did positive expression of $\alpha$-SMA in tumour cells of recurrent BCC $(p=0.002)$. In the group of primary aggressive BCC subtypes, reduced expression of MOC-31 was also associated with a higher rate of relapse $(p=0.02)$.

Conclusions: Our findings provide information about $\alpha$-SMA and MOC-31 expression in primary and recurrent BCCS. These data may contribute to the formulation of a more targeted treatment plan and follow-up strategy for patients with facial basal cell carcinoma.
\end{abstract}

Key words: basal cell carcinoma, prognostic factors, $\alpha$-smooth muscle actin, MOC-31, Ber-EP4.

\section{Introduction}

Basal cell carcinoma (BCC) is the most common type of skin cancer [1-3]. Although BCC metastases are extremely rare, their relatively high recurrence rate results in significant morbidity. Treatment of facial BCC remains a challenge for surgeons. BCC is often diagnosed at an advanced stage, after it had already damaged the function of important facial structures and, even after extensive surgery, gives questionable aesthetic results [2, 4].

Biopsy remains the gold standard in the diagnosis of skin cancer. Based on the biopsy results, the cancer type and subtype are determined and a decision regarding treatment is made. In the past decade, a number of stud- ies were conducted to investigate the molecular basis of skin cancer. Immunohistochemical markers have been shown to provide information that can help to predict the course and risk of recurrence of BCC. Tumour invasive potential depends, among other things, on cell motility and the ability to migrate into the surrounding tissues. Microfilaments, which contain $\alpha$-smooth muscle actin ( $\alpha$-SMA) are largely responsible for cell motility [5]. Qualitative and quantitative changes in $\alpha$-SMA expression in tumour cells and stroma may correlate with aggressiveness of tumour growth [6]. Another important factor contributing to the invasiveness of BCC cells is adhesion abnormalities between cells and the intercellular matrix. E-cadherins (EC) play an

Address for correspondence: Katarzyna Iwulska MD, DDS, PhD, Department of Cranio-Maxillofacial, Oncological and Reconstructive Surgery, Jagiellonian University Medical College, Krakow, Poland, phone: +48 501684 198, fax: +48 1240028 17, e-mail: iwulska@gmail.com Received: 17.05 .2020 , accepted: 5.08.2020. 
important role in normal cell adhesion [7]. Co-expression of EC and epithelial cell adhesion molecules (Ep-CAM) can be demonstrated in the majority of epithelial cells. Ep-CAM is known to be a marker of human epithelial tissues and malignant tumours of epithelial origin. According to the recent studies, there is a cross-signalling pathway between the Ep-CAM system and the classic adhesion molecules in tumour epithelial cells, which takes part in the process of cell proliferation [8]. Monoclonal antibodies; Ber-EP4 and MOC-31, can be used to detect the external domain of the Ep-CAM molecule [8].

\section{Aim}

The aim of the study was to analyse the expression of selected immunohistochemical markers ( $\alpha$-SMA, E-cadherin, Ber-Ep4, MOC-31) as predictors of local recurrence in a group of patients with primary and recurrent BCCs of the face in correlation with histological and clinical data.

\section{Material and methods}

\section{Patients and clinicopathological data}

The study cohort included 79 formalin-fixed, paraffinembedded excisional tumour samples harvested from patients with BCC of the face who were treated at the Department of Cranio-Maxillofacial Surgery of the JagielIonian University, Krakow in 1997-2009. All patients underwent simple surgical excision of the tumour with at least $5 \mathrm{~mm}$ margin. In 27 cases, an intraoperative margin assessment was performed. The specimens were divided into two groups: group I consisted of 52 cases of primary BCC (27 aggressive and 25 non-aggressive BCC subtypes) and group II of 27 cases of recurrent BCC (18 aggressive and 9 non-aggressive BCC subtypes). With regards to the histological subtype; 13 of the patients with aggressive BCC had an infiltrative, 5 a metatypical, 1 a micronodular and 26 a mixed tumour (with at least one aggressive component). The group of patients with non-aggressive BCC was comprised of 30 nodular and 4 tumours with adnexal differentiation. Clinical information was obtained from the patients' medical records. This research was approved by the Bioethics Committee of the Jagiellonian University.

\section{Histological re-evaluation and Immunohistochemistry}

All specimens underwent histological re-examination including confirmation of the BCC subtype according to the WHO (2005) histological classification of keratinocytic skin tumours, pT, pN classification (TNM 2012), detection of the presence of neural invasion and reassessment of margins of excision. Non-radical excision of the tumour was defined as excision with a margin of healthy tissue of less than $0.5 \mathrm{~mm}$.

For immunohistochemical examination, formalinfixed, paraffin-embedded excisional BCC specimens were cut into $3 \mu \mathrm{m}$ thick sections. After deparaffinization (in serial xylene washes) and rehydration (in a series of decreasing concentrations of alcohols), sections were heated in citrate buffer or digested with proteinase $\mathrm{K}$ and incubated for 10 min in 3-percent hydrogen peroxide $\left(\mathrm{H}_{2} \mathrm{O}_{2}\right)$ solution to block endogenous peroxidase activity. The specimens were later incubated overnight at $4{ }^{\circ} \mathrm{C}$ with primary antibodies against E-cadherin (Dako NCH-38, dilution factor (df) 1 : 1200), $\alpha$-SMA (Dako 1A4, df $1:$ 1200), Ber-Ep4 (Dako Ber-Ep4, df $1: 1200$ ) and MOC-31 antigens (Cell-Marque, df $1: 1200$ ). A detailed description of the antibodies is presented in Table 1 . After incubation, sections were washed twice in TBS buffer, and then, the Poly-HRP-GAM/R/R IgG (Immunologic) detection system for murine and rabbit primary antibodies was applied. 3,3-diaminobenzidine tetrachloride (DAB, Dako) enabled visualization of the reaction. Following completion of the reaction, the sections were counterstained with Meyer's haematoxylin (2 min), dehydrated in a series of increasing concentrations of alcohols, washed in xylene and then mounted. Tissue sections have been semi-quantified by the pathologist visual scoring of staining. All scores were evaluated independently by a pathologist and trained assistant. The pathologists who evaluated the immunohistochemical reactions were not informed about the clinical course of the cancer. The specimens were assessed using a Leica Microsystems DLMB type (2001) biological microscope.

\section{Ethical approval}

This study was approved by the Bioethics Committee of the Jagiellonian University (KBNET/79/B/2012). In the study a retrospective analysis of the patients' medical records with pathological reassessment and immunohistochemical re-examination of harvested excisional tumour samples was performed.

All procedures performed in studies involving human participants' specimens were in accordance with the ethical standards of the institutional and/or national research committee and with the 1964 Helsinki declaration and its later amendments or comparable ethical standards.

\section{Statistical analysis}

The association between clinicopathological features and the significance of different prognostic markers was evaluated using the $\chi^{2}$ test, and in the case of groups with small numbers - the Fisher exact test. Analysis of prognostic indicators was performed with the Cox regression and logistic model. A graphic analysis of disease-free survival (DFS) was illustrated with the Kaplan-Meier plot with the log-rank test. Calculations were performed using the statistical software package Stata 12.0. Statistical significance was defined as $p \leq$ 0.050 . 


\section{Results}

\section{Demographic and clinical data}

The mean age of the patients was $68.4 \pm 12.8$ years and the male to female ratio was 1.4. Lesions were located on the cheek $-24(30.4 \%)$, nose $-20(25.3 \%)$, in the orbital region - 17 (21.5\%), temple - 9 (11.4\%), forehead -5 (6.3\%), and skin of the lips and chin -4 (5.1\%). Twenty-seven patients (34.2\%) were referred to our department in stage T1, according to TNM (2012) classification, 15 (19\%) in stage T2, 29 (36.7\%) in T3 and 8 patients (10.1\%) in T4. There were no statistically significant differences between groups I and II regarding age, sex, aggressiveness of BCC subtype, tumour location and TNM (2012). The patients were followed-up for an average period of 6.7 years (from 1 to 15 years).

\section{BCC local recurrence prognostic factors}

The prevalence of incomplete tumour excision was higher in the group of patients with recurrent BCC, compared to primary BCC $(n=17 ; 32.7 \%$ vs. $n=17 ; 62.9 \%$, $p=0.016)$. The recurrence rate was also higher in patients with recurrent (group II) compared to primary (group I) BCC ( $n=13 ; 48.2 \%$ vs. $n=7 ; 13.5 \% ; p=0.002$ ). The median time to relapse was $30.2 \pm 17.8$ months. In the group of patients with aggressive histological subtypes of BCC there was a higher incidence of local recurrence compared to non-aggressive BCC (33.3\% vs. 14.7\%; $p=0.07$ ), especially in patients with primary tumours (22.2\% vs. $4 \%$ ). Univariate analysis with a Cox proportional hazards model which included covariates such as age and sex revealed the following risk factors to be significant for local recurrence: recurrent tumour $(O R=4.61$; 95\% Cl: 1.83-11.6; $p=0.001)$, multifocal BCC (OR = 3.12; $95 \% \mathrm{Cl}: 1.28-7.56 ; p=0.01)$, incomplete tumour excision $(\mathrm{OR}=2.95 ; 95 \% \mathrm{Cl}: 1.17-7.42 ; p=0.02)$ and aggressive infiltrating histologic subtype of BCC $(\mathrm{OR}=2.5 ; 95 \% \mathrm{Cl}$ : 0.99-6.28; $p=0.05$ ) (Table 2).

\section{Markers of expression in primary and recurrent tumours}

There was no statistically significant difference in the expression of intracellular E-cadherin, Ber-Ep4, MOC-31 and $\alpha$-SMA between primary and recurrent tumours. Positive Ber-Ep4 expression was observed in 73 of 79 BCC specimens (92\%). Positive reactivity for MOC-31 was demonstrated in 75 of 79 BCC cases (95\%) (Figure 1).

\section{$\alpha-S M A$ expression in primary and recurrent tumours}

Positive expression of $\alpha$-SMA was a predisposing factor for local recurrence. In the group of patients with primary BCC, positive expression of stromal $\alpha-S M A$ $(p=0.03)$ was correlated with a statistically significant higher recurrence rate and so was positive expression

Table 1. Markers of expression in primary and recurrent BCCs of the face

\begin{tabular}{|c|c|c|c|c|}
\hline \multirow[t]{2}{*}{ Expression } & \multicolumn{4}{|c|}{ Local recurrence } \\
\hline & Primary BCC & $P$-value & Recurrent BCC & $P$-value \\
\hline \multicolumn{5}{|l|}{$\alpha-\mathrm{tSMA}:$} \\
\hline Not present & $5(22.7 \%)$ & \multirow[t]{2}{*}{0.11} & $6(30.0 \%)$ & \multirow[t]{2}{*}{0.002} \\
\hline Present & $2(6.7 \%)$ & & 7 (100.0\%) & \\
\hline \multicolumn{5}{|l|}{$\alpha$-sSMA: } \\
\hline Not present & $0(0 \%)$ & \multirow[t]{5}{*}{0.03} & $2(40.0 \%)$ & \multirow[t]{5}{*}{1.00} \\
\hline$<25 \%$ & $2(16.7 \%)$ & & $2(66.7 \%)$ & \\
\hline $25-50 \%$ & $3(27.3 \%)$ & & $2(50.0 \%)$ & \\
\hline $50-75 \%$ & $1(7.1 \%)$ & & $7(46.7 \%)$ & \\
\hline$>75 \%$ & $1(100.0 \%)$ & & $0(0 \%)$ & \\
\hline \multicolumn{5}{|l|}{ EC: } \\
\hline Not present & $3(13.0 \%)$ & \multirow[t]{2}{*}{1.00} & $6(46.2 \%)$ & \multirow[t]{2}{*}{1.00} \\
\hline Present & $4(13.8 \%)$ & & $7(50.0 \%)$ & \\
\hline \multicolumn{5}{|l|}{ Ber-EP4: } \\
\hline$<50 \%$ & $5(14.7 \%)$ & \multirow[t]{2}{*}{1.00} & $8(44.4 \%)$ & \multirow[t]{2}{*}{1.00} \\
\hline$>50 \%$ & $2(13.3 \%)$ & & $3(50.0 \%)$ & \\
\hline \multicolumn{5}{|l|}{ MOC-31: } \\
\hline$<50 \%$ & $6(23.1 \%)$ & \multirow[t]{2}{*}{0.09} & $6(42.9 \%)$ & \multirow[t]{2}{*}{1.00} \\
\hline$>50 \%$ & $1(4.0 \%)$ & & $5(50.0 \%)$ & \\
\hline
\end{tabular}

$\alpha-t S M A-\alpha-S M A$ in tumour cells, $\alpha$-SSMA - stromal $\alpha-S M A$. 

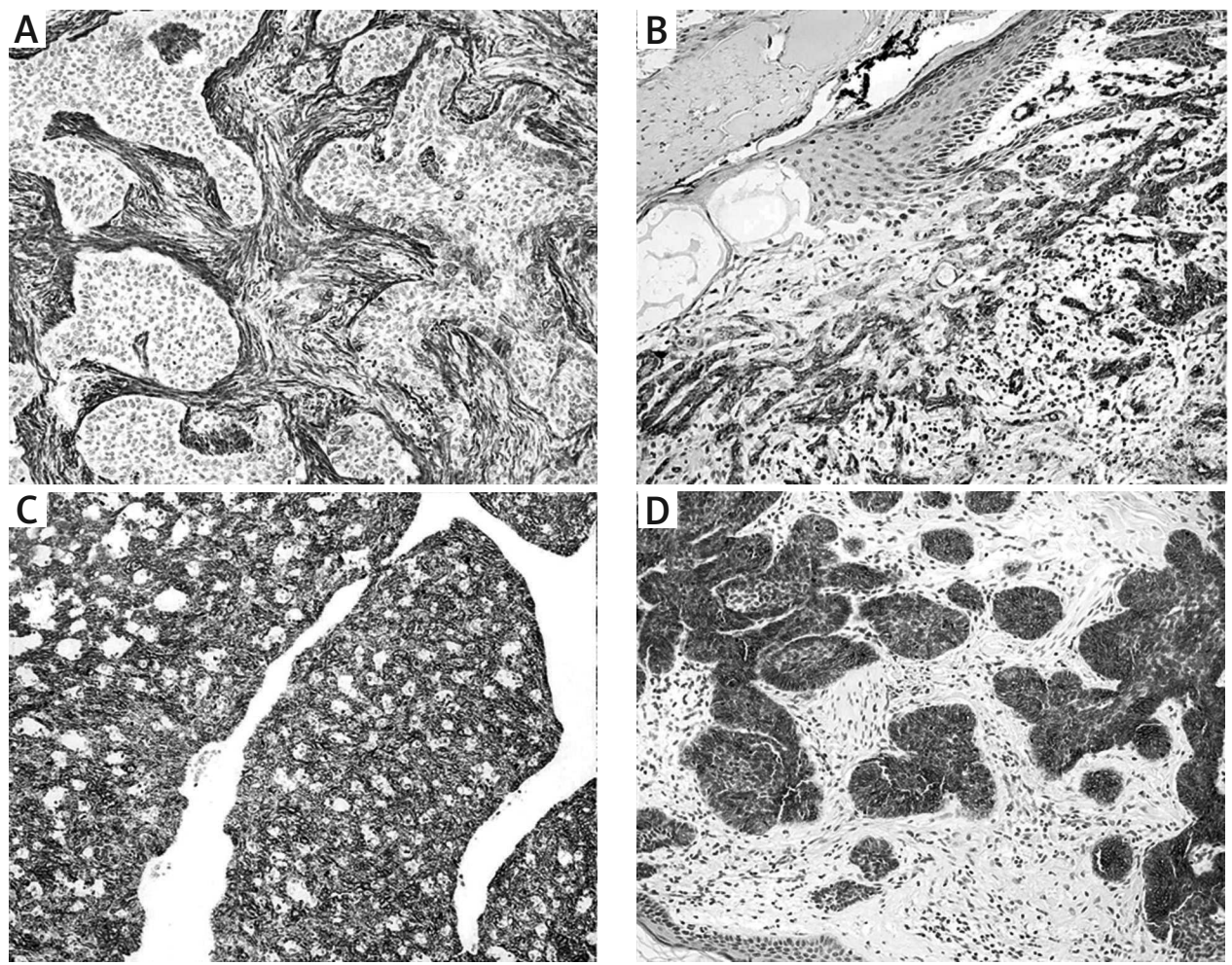

Figure 1. $\alpha$-SMA expression in primary BCC (A); $\alpha$-SMA expression in recurrent BCC (B); Ber-EP4 expression in BCC (C); MOC-31 expression in BCC (D). Original magnification 20x (for all photomicrographs)

Table 2. Univariate Cox regression analysis for local relapse predictors in primary and recurrent BCCs

\begin{tabular}{llll}
\hline Parameter & HR & $95 \% \mathrm{Cl}$ & $P$-value \\
\hline Sex & 0.99 & $0.40-2.42$ & 0.98 \\
\hline Age $>$ 60 years & 0.59 & $0.24-1.46$ & 0.26 \\
\hline TNM: & & & \\
\hline pT 2,3,4 & 1.97 & $0.78-4.95$ & 0.14 \\
\hline pN+ & 1.06 & $0.14-7.96$ & 0.95 \\
\hline Recurrent tumour & 4.61 & $1.83-11.60$ & 0.001 \\
\hline Multifocal BCC & 3.12 & $1.28-7.56$ & 0.01 \\
\hline Incomplete excision & 2.95 & $1.17-7.42$ & 0.02 \\
\hline Aggressive BCC subtype & 2.49 & $0.90-6.87$ & 0.07 \\
\hline Infiltrating BCC subtype & 2.50 & $0.99-6.28$ & 0.05 \\
\hline Depth of infiltration $>4 \mathrm{~mm}$ & 2.94 & $0.82-10.44$ & 0.09 \\
\hline Perineural infiltration & 1.22 & $0.40-3.67$ & 0.71
\end{tabular}

of $\alpha$-SMA in the tumour cells of patients with recurrent BCC ( $p=0.002)$ (Table 1$)$. The 10-year recurrencefree survival rate was lower in patients with recurrent BCC tumour cells positive for $\alpha$-SMA expression compared to patients without expression of this marker $(p<0.0001)$ (Figure 2).

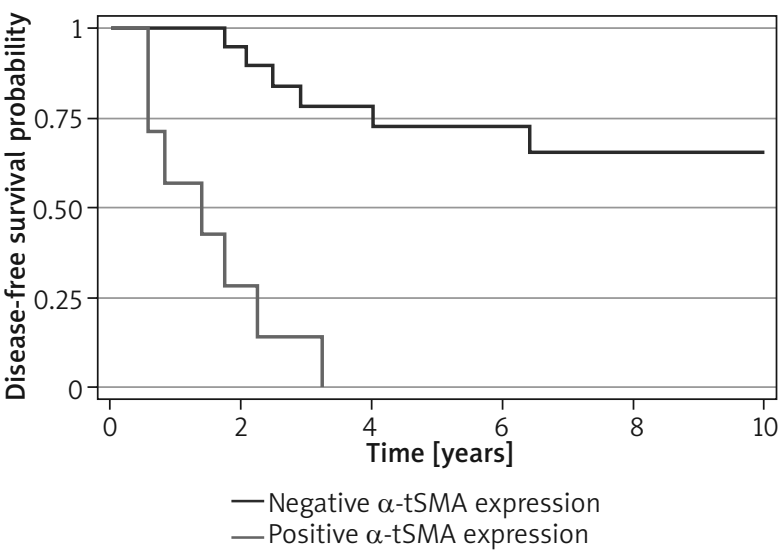

Figure 2. 10-year Kaplan-Meier disease-free survival curves stratified for $\alpha$-SMA expression in tumour cells ( $\alpha$-tSMA) in a group of patients with recurrent BCC

$\alpha$-SMA and MOC-31 expression in aggressive bcc subtypes

In the group of patients with primary aggressive BCC subtypes, reduced expression of MOC-31 (<50\%) was associated with a higher recurrence rate $(p=0.02)$. In addition, positive expression of $\alpha$-SMA in the stromal tissue was associated with a tendency toward local disease relapse $(p=0.06)$. In the group of patients with recurrent aggressive BCC, positive expression of $\alpha$-SMA 
Table 3. Markers of expression in primary and recurrent aggressive BCC subtypes of the face

\begin{tabular}{|c|c|c|c|c|}
\hline \multirow[t]{2}{*}{ Expression } & \multicolumn{4}{|c|}{ Local recurrence } \\
\hline & Primary aggressive $\mathrm{BCC}$ & $P$-value & Recurrent aggressive $\mathrm{BCC}$ & $P$-value \\
\hline \multicolumn{5}{|l|}{$\alpha$-tSMA: } \\
\hline Not present & $4(33.3 \%)$ & \multirow[t]{2}{*}{0.35} & $4(30.77 \%)$ & \multirow[t]{2}{*}{0.02} \\
\hline Present & $2(13.3 \%)$ & & $5(100.0 \%)$ & \\
\hline \multicolumn{5}{|l|}{$\alpha$-sSMA: } \\
\hline Not present & $0(0 \%)$ & \multirow[t]{5}{*}{0.06} & $1(100.0 \%)$ & \multirow[t]{5}{*}{0.46} \\
\hline$<25 \%$ & $1(20.0 \%)$ & & $2(100.0 \%)$ & \\
\hline $25-50 \%$ & $3(50.0 \%)$ & & $1(33.3 \%)$ & \\
\hline $50-75 \%$ & $1(10.0 \%)$ & & $5(41.7 \%)$ & \\
\hline$>75 \%$ & $1(100.0 \%)$ & & $0(0 \%)$ & \\
\hline \multicolumn{5}{|l|}{ EC: } \\
\hline Not present & $2(28.6 \%)$ & \multirow[t]{2}{*}{0.63} & $2(40.0 \%)$ & \multirow[t]{2}{*}{1.00} \\
\hline Present & $4(20.0 \%)$ & & $7(53.9 \%)$ & \\
\hline \multicolumn{5}{|l|}{ Ber-EP4: } \\
\hline$<50 \%$ & $5(27.8 \%)$ & \multirow[t]{2}{*}{0.62} & $6(42.9 \%)$ & \multirow[t]{2}{*}{0.57} \\
\hline$>50 \%$ & $1(12.5 \%)$ & & $2(66.7 \%)$ & \\
\hline \multicolumn{5}{|l|}{ MOC-31: } \\
\hline$<50 \%$ & $6(40.0 \%)$ & \multirow[t]{2}{*}{0.02} & $4(40.0 \%)$ & \multirow[t]{2}{*}{0.63} \\
\hline$>50 \%$ & $0(0 \%)$ & & $4(57.1 \%)$ & \\
\hline
\end{tabular}

$\alpha-t S M A-\alpha-S M A$ in tumour cells, $\alpha$-SSMA - stromal $\alpha-S M A$.

Table 4. Multivariate Cox regression analysis for local recurrence predictors in the group of recurrent aggressive BCC subtypes of the face

\begin{tabular}{lccc}
\hline Local recurrence predictors & HR & \multicolumn{1}{c}{$95 \% \mathrm{Cl}$-value } & 0.30 \\
\hline Sex & 2.96 & $0.37-23.37$ & $0.05-4.03$ \\
\hline Age $>60$ years & 0.47 & 0.49 & $0.10-13.53$ \\
\hline Aggressive (infiltrating) BCC subtype & 1.21 & $0.49-43.05$ & 0.17 \\
\hline Incomplete excision & 4.63 & 6.51 & 0.03 \\
\hline Positive expression of $\alpha$-SMA in tumour cells & & 0.37 .96 \\
\hline
\end{tabular}

in tumour cells was associated with local recurrence ( $p=0.02)$ (Table 3).

In the group of recurrent aggressive BCC, a multivariate Cox regression model demonstrated that positive expression of $\alpha$-SMA was an independent predictor of local recurrence of the tumour $(\mathrm{HR}=6.51 ; 95 \% \mathrm{Cl}: 1.11-37.96$, $p=0.03)$ (Table 4).

\section{Discussion}

The relatively high recurrence rate of facial BCC depends on various risk factors. This study revealed the following risk factors to be significant for local recurrence: recurrent tumour $(\mathrm{OR}=4.61 ; 95 \% \mathrm{Cl}: 1.83-11.6$; $p=0.001)$, multifocal BCC (OR = 3.12; 95\% Cl: 1.28-7.56; $p=0.01)$, incomplete tumour excision $(\mathrm{OR}=2.95 ; 95 \%$
$\mathrm{Cl}: 1.17-7.42 ; p=0.02)$ and the aggressive infiltrating histologic subtype of $\mathrm{BCC}(\mathrm{OR}=2.5$; 95\% Cl: 0.99-6.28; $p=0.05)$. These findings are consistent with the report of Kyrgidis et al. [1] concerning a group of 1062 patients with primary BCC of the head and neck region. According to their analysis, the risk of recurrence was increased in the case of incomplete tumour excision $(\mathrm{OR}=4.31,95 \% \mathrm{Cl}$ : $1.82-10.22, p=0.001)$, aggressive BCC subtype (OR $=3.47$, $95 \% \mathrm{Cl}: 1.07-11.25, p=0.038)$ and a prior history of BCC $(\mathrm{OR}=2.86,95 \% \mathrm{Cl}: 1.54-5.34, p=0.001)$. Based on the study, the strongest predictors of recurrence were positive excision margins and a high-risk histology. These factors have been confirmed by many other authors. Cumulative 5-year recurrence rates after surgical excision are significantly lower for primary BCCs (4.8\%) than recurrent tumours (11.6\%) [6]. Szewczyk et al. revealed 
that in the group of head and neck BCC, recurrence occurred in $9 \%$ of primary tumours and $17 \%$ of recurrent lesions [9]. Another factor strongly associated with relapse of facial BCC is incomplete tumour resection at primary surgery [10]. Recurrence rates among patients with positive margins varies from $10 \%$ to $67 \%$ compared to $0.35-14 \%$ after complete resection of the lesion [11-13]. There is also a strong correlation between relapse and aggressive BCC subtype. The incidence of recurrence of the infiltrating subtype is higher (26-27.7\%) than nodular one (6.4-8.2\%) [13-16]. High-risk histology BCC subtypes tend to have about a 3.8 times higher extensive subclinical spread than primary nodular BCC, which results in more frequent positive surgical margins [17].

Nowadays many studies of potential molecular biomarkers are conducted to determine new prognostic factors of BCC behaviour. The expression pattern of cancer associated fibroblasts (CAFs)-related proteins in tumour stroma may play a crucial role in the formation of the tumour microenvironment and its contribution to tumour invasiveness and metastasis [18]. According to available reports, qualitative and quantitative changes in the expression of $\alpha$-SMA may correlate with aggressive tumour growth [6]. However, reports about the role of $\alpha$-SMA as a marker of aggressiveness of BCC and its expression in the tumour and in the surrounding stroma are not consistent. Gabbiani et al. found that in normal epithelial cells the actin content is minimal, while in the BCC cells those contractile proteins are stained most intensively at the edge of the growing tumour and in isolated tumour cells surrounding the blood and lymphatic vessels [19]. Tumour cells may secrete cytokine, which leads to abnormal actin expression [6]. In contrast, actin within the stroma is a marker of myofibroblasts, which secrete matrix-degrading metalloproteinases called stromelysin-3 and facilitate the motility and invasiveness of BCC tumour cells $[5,6]$. Our study showed that both the expression of $\alpha$-SMA in tumour cells and stroma were prognostic factors. In the group of primary tumours, positive expression of stromal $\alpha$-SMA correlated with a higher recurrence rate $(p=0.03)$. In the case of recurrent $\mathrm{BCC}$, positive expression of $\alpha$-SMA in tumour cells $(p=0.002)$ predisposed to local recurrence. Moreover, in the group of aggressive recurrent BCC, higher $\alpha$-SMA expression in tumour cells has proven to be an independent predictor of recurrence $(p=0.02)$. We were unable to find any publications that demonstrated a direct correlation between $B C C$ recurrence and $\alpha$-SMA staining. The literature reports a correlation between $\alpha$-SMA and aggressive BCC subtypes, which reoccur more frequently $[1,6,20]$. Christian et al. revealed that $67 \%$ (6 out of 9) of micronodular subtypes and $62 \%$ (8 of 13 ) of morpheaform subtypes stained positive for $\alpha$-SMA compared to $0 \%$ (0 of 12) of nodular subtypes. Their study group consisted of 32 primary and 2 recurrent tumours. Expression of $\alpha$-SMA was considered positive either in the tumour cells or stroma, but in case of recurrent tumours - only in the tumour cells (due to positive staining of the scar for $\alpha$-SMA). The authors hypothesized that the presence of $\alpha$-SMA in the surrounding stroma may be a predictor of aggressive invasion [6]. Similar results were also obtained by other researchers [21-23]. Law et al. compared actin expression in the tumour cells and stroma of 7 purely nodular BCCS and 13 mixed nodular-infiltrative BCCs and they found that there was a statistically significant difference in staining of $\alpha$-SMA between those two groups. There is no information in the article on whether these were primary or recurrent tumours [5]. Adegboyega et al. also found a statistically significant correlation between the expression of $\alpha$-SMA in the stroma and invasive growth of BCC. The expression of $\alpha$-SMA in the tumour cells was higher in aggressive BCC than in the control group, but the difference was not statistically significant. The inclusion criteria of their study group (aggressive BCC) included: history of 3 or more recurrences, tumour size $>3 \mathrm{~cm}$, infiltration of cartilage, bone, and parotid gland [24]. With regards to $\alpha$-SMA staining in the cytoplasm of the tumour cells, Papanikolaou et al. documented a strong positive correlation between the expression levels of $\alpha$-SMA and the depth of tumour invasion. Expression of $\alpha$-SMA was also significantly higher in infiltrative compared to nodular BCC variants. There was no information on whether these BCCs were primary or recurrent [7]. Uzquiano et al. also noted decreased $\alpha$-SMA expression in nodular BCC compared to the infiltrating subtype. The authors did not evaluate the expression of $\alpha$-SMA in the stroma and the character of the tumour (primary vs recurrent) was not specified [25].

E-cadherins (EC) are the central components of adherents junctions and their functional disorders may lead to a loss in cell adhesion and promote invasive tumour growth and tumour progression. In our study there was no statistically significant difference in the expression of intracellular E-cadherin(s) between primary and recurrent tumours. In the literature, higher cytoplasmic and nuclear E-cadherin immunopositivity has been found to be related to increasing depth of tumour invasion and the infiltrative variant of BCC (compared with nodular BCC) [7]. We have found a similar correlation, but this is not the main focus of the article.

Ep-CAM is another molecule involved in cell adhesion, signalling, migration, proliferation and differentiation [8]. Anti-EpCAM antibodies can be used for both diagnostic and therapeutic purposes [26]. Ber-EP4 can be used as a marker to confirm the diagnosis of BCC as well as detect the presence of metastasis or cancer cells during Mohs micrographic surgery [2, 27-30]. In addition, this antigen has not been found in normal keratinocytes or in squamous cell carcinoma [28]. In the literature, positive Ber-EP4 staining has been described in $80-100 \%$ of studied BCC samples [26-31]. MOC-31 is a monoclonal antibody, which can bind to malignant epithelial tu- 
mours from various anatomic sites [32]. MOC-31 even has a higher sensitivity in the detection of invasive lobular and ductal breast carcinoma than Ber-EP4 [8]. With regards to the skin, Merkel cell carcinoma, metastatic visceral neuroendocrine carcinomas, sebaceous neoplasms, primary sweat gland carcinomas, metastatic squamous carcinomas and adenocarcinomas may be reactive with MOC-31 [33]. Webb et al. showed that metatypical BCC demonstrated strong and diffuse staining with both BerEP4 (29/29) and MOC-31 (25/29). They assumed that MOC-31 could be a useful additional reliable discriminant in the differential diagnosis of metatypical BCC and basaloid squamous cell carcinoma [33]. Those reports are coherent with our study, in which positive Ber-Ep4 expression was observed in $92 \%$ of BCC specimens (73/79) and MOC-31 reactivity - in 95\% of BCC cases (75/79).

We were not able to find any publications in the available literature discussing the role of $\mathrm{MOC}-31$ in $\mathrm{BCC}$ recurrence. $M O C-31$ is a known prognostic marker for various cancers such as breast, lung, genital tract, pancreas, colon, stomach, oesophagus, prostate, head and neck, liver and kidney [8, 32]. Our study revealed that in the group of primary aggressive BCC subtypes, reduced expression of MOC-31 (<50\%) was related to a higher local recurrence rate $(p=0.02)$. Similar results were obtained in many studies concerning different malignancies. The authors have shown a relationship between reduced Ep-CAM expression and shorter survival of patients with aggressive and anaplastic subtypes of thyroid cancer, gastric cancer and carcinoma of the ampulla of Vater [34-36]. Loss of membrane expression of Ep-CAM was also associated with and a higher risk of metastasis $(p=0.02)$ and invasive growth $(p=0.005)$ of colon and rectum cancer [37]. On the other hand, some authors report that in breast, lung, bladder or ovarian cancers, overexpression of the extracellular domain of Ep-CAM is related to a poorer prognosis [38]. The significance of MOC-31 expression in BCC and its prognostic value is difficult to elucidate due to the limited number of studies on this subject. Both the strong expression and the loss of immunoreactivity of the extracellular domains of the Ep-CAM molecule in different tumours may be explained by the process of proteolysis. Depending on the microenvironment, different proteolytic pathways can lead to Ep-CAM cleavage in multiple sites [39]. Warneke et al. have shown that lack of immunodetection of the extracellular Ep-CAM domain is not accompanied by a decreased level of its mRNA within the nucleus [36]. However, further studies are necessary to evaluate Ep-CAM function in BCC.

\section{Acknowledgments}

This study was supported by the Ministry of Science and Higher Education funds (K/DSC/00736).

\section{Conflict of interest}

The authors declare no conflict of interest.

\section{References}

1. Kyrgidis A, Vahtsevanos K, Tzellos TG, et al. Clinical, histological and demographic predictors for recurrence and second primary tumours of head and neck basal cell carcinoma. A 1062 patient-cohort study from tertiary cancer referral hospital. Eur I Dermatol 2010; 20: 276-82.

2. Lesiak A, Czuwara J, Kamińska-Winciorek G, et al. Basal cell carcinoma. Diagnostic and therapeutic recommendations of Polish Dermatological Society. Przegl Dermatol 2019; 106: 107-26.

3. Yan F, Knochelmann, HM, Morgan PF, et al. The evolution of care of cancers of the head and neck region: state of the science in 2020. Cancers 2020; 12: 1543.

4. Bartoš V, Pokorný D, Zacharová O, et al. Recurrent basal cell carcinoma: a clinicopathological study and evaluation of histomorphological findings in primary and recurrent lesions. Acta Dermatovenerol Alp Pannonica Adriat 2011; 20: 67-75.

5. Law AM, Oliveri CV, Pacheco-Quinto X, Horenstein MG. Actin expression in purely nodular versus nodular-infiltrative basal cell carcinoma. J Cutan Pathol 2003; 30: 232-6.

6. Christian MM, Moy RL, Wagner RF, Yen-Moore A. A correlation of alpha-smooth muscle actin and invasion in $\mathrm{mi}$ cronodular basal cell carcinoma. Dermatol Surg 2001; 27: 441-5.

7. Papanikolaou S, Bravou V, Gyftopoulos K, et al. ILK expression in human basal cell carcinoma correlates with epithelial-mesenchymal transition markers and tumour invasion. Histopathology 2010; 56: 799-809.

8. Pai RK, West RB. MOC-31 exhibits superior reactivity compared with Ber-EP4 in invasive lobular and ductal carcinoma of the breast: a tissue microarray study. Appl Immunohistochem Mol Morphol 2009; 17: 202-6.

9. Szewczyk MP, Pazdrowski J, Danczak-Pazdrowska A, et al. Analysis of selected recurrence risk factors after treatment of head and neck basal cell carcinoma. Adv Dermatol Allergol 2014; 31: 146-51.

10. Troeltzsch M, Probst FA, Knösel T, et al. Clinical and pathologic parameters predicting recurrence of facial basal cell carcinoma: a retrospective audit in an advanced care center. Int J Dermatol 2016; 55: 1281-8.

11. Griffiths RW, Suvarna SK, Stone J. Do basal cell carcinomas recur after complete conventional surgical excision? Br J Plast Surg 2005; 58: 795-805.

12. Nagore E, Grau C, Molinero J, Fortea JM. Positive margins in basal cell carcinoma: relationship to clinical features and recurrence risk. A retrospective study of 248 patients. J Eur Acad Dermatol Venereol 2003; 17: 167-70.

13. Santiago F, Serra D, Vieira R, Figueiredo A Incidence and factors associated with recurrence after incomplete excision of basal cell carcinomas: a study of 90 cases. J Eur Acad Dermatol Venereol 2010; 24: 1421-4.

14. Sexton M, Jones DB, Maloney ME. Histologic pattern analysis of basal cell carcinoma. Study of a series of 1039 consecutive neoplasms. J Am Acad Dermatol 1990; 23: 1118-26.

15. Sloane JP. The value of typing basal cell carcinomas in predicting recurrence after surgical excision. Br J Dermatol 1977; 96: 127-32.

16. Zagrodnik B, Kempf W, Seifert B, et al. Superficial radiotherapy for patients with basal cell carcinoma: recurrence rates, histologic subtypes, and expression of p53 and Bcl-2. Cancer 2003; 98: 2708-14.

17. Batra RS, Kelley LC. A risk scale for predicting extensive subclinical spread of nonmelanoma skin cancer. Dermatol Surg 2002; 28: 107-12. 
18. Sasaki K, Sugai T, Ishida K, et al. Analysis of cancer-associated fibroblasts and the epithelial-mesenchymal transition in cutaneous basal cell carcinoma, squamous cell carcinoma, and malignant melanoma. Hum Pathol 2018;79: 1-8.

19. Gabbiani G, Csank-Brassert J, Schneeberger JC, et al. Contractile proteins in human cancer cells. Immunofluorescent and electron microscopic study. Am J Pathol 1976; 83: 457-74.

20. Shamsi Meymandi S, Dabiri S, Zeynadini Meymand A, et al. Evaluation of immunohistochemical findings and clinical features associated with local aggressiveness in basal cell carcinoma. Iran J Pathol 2019; 14: 193-6.

21. Bartoš V, Doboszová J. Immunohistochemical expression of smooth muscle actin in basal cell carcinoma of the skin. Dermatol Prax 2014; 8: 98-101.

22. Mercut R, Ciurea ME, Mărgăritescu C, et al. Expression of p53, D2-40 and $\alpha$-smooth muscle actin in different histological subtypes of facial basal cell carcinoma. Rom J Morphol Embryol 2014; 55: 263-72.

23. Motegi S, Yamada K, Ishikawa O. Twist1 in tumor cells and $\alpha$-smooth muscle actin in stromal cells are possible biomarkers for metastatic giant basal cell carcinoma. J Dermatol 2013; 40: 661-3.

24. Adegboyega PA, Rodriguez S, McLarty J. Stromal expression of actin is a marker of aggressiveness in basal cell carcinoma. Hum Pathol 2010; 41: 1128-37.

25. Uzquiano MC, Prieto VG, Nash JW, et al. Metastatic basal cell carcinoma exhibits reduced actin expression. Modern Pathology 2008; 21: 540-3.

26. Dasgeb B, Mohammadi TM, Mehregan DR. Use of Ber-EP4 and epithelial specific antigen to differentiate clinical simulators of basal cell carcinoma. Biomark Cancer 2013; 25: 7-11.

27. Beer TW, Shepherd P, Theaker JM. Ber EP4 and epithelial membrane antigen aid distinction of basal cell, squamous cell and basosquamous carcinomas of the skin. Histopathology 2002; 37: 218-23.

28. Karahan N, Baspinar S, Yildirim M, Barut I. The use of BerEP4 antigen in the differential diagnosis of basosquamous carcinoma from squamous and basal cell carcinoma. Türk Patoloji Dergisi 2006; 22: 87-9.

29. Kist D, Perkins W, Christ S, Zachary CB. Anti-human epithelial antigen (Ber-EP4) helps define basal cell carcinoma masked by inflammation. Dermatol Surg 1997; 23: 1067-70.

30. Tellechea O, Reis JP, Domingues JC, Baptista AP. Monoclonal antibody Ber EP4 distinguishes basal cell carcinoma from squamous-cell carcinoma of the skin. Am I Dermatopathol 1993; 15: 452-5.

31. Ansai S, Takayama R, Kimura T, Kawana S. Ber-EP4 is a useful marker for follicular germinative cell differentiation of cutaneous epithelial neoplasms. J Dermatol 2012; 39: 688-92.

32. Winter MJ, Nagtegaal ID, van Krieken JH, Litvinov SV. The epithelial cell adhesion molecule (Ep-CAM) as a morphoregulatory molecule is a tool in surgical pathology. Am J Pathol 2003; 163: 2139-48.

33. Webb DV, Mentrikoski MJ, Verduin L, et al. Basal cell carcinoma vs basaloid squamous cell carcinoma of the skin: an immunohistochemical reappraisal. Ann Diagn Pathol 2015; 19: 70-5.

34. Ralhan R, Cao J, Lim T, et al. EpCAM nuclear localization identifies aggressive thyroid cancer and is a marker for poor prognosis. BMC Cancer 2010; 25: 331.

35. Piscuoglio S, Lehmann FS, Zlobec I, et al. Effect of EpCAM, CD44, CD133 and CD166 expression on patient survival in tumours of the ampulla of Vater. J Clin Pathol 2012; 65: 140-5.
36. Warneke VS, Behrens HM, Haag J, et al. Members of the EpCAM signalling pathway are expressed in gastric cancer tissue and are correlated with patient prognosis. Br J Cancer 2013; 109: 2217-27.

37. Lugli A, lezzi G, Hostettler I, et al. Prognostic impact of the expression of putative cancer stem cell markers CD133, CD166, CD44s, EpCAM, and ALDH1 in colorectal cancer. Br J Cancer 2010; 103: 382-90.

38. van der Gun BT, Melchers LJ, Ruiters MH, et al. EpCAM in carcinogenesis: the good, the bad or the ugly. Carcinogenesis 2010; 31: 1913-21.

39. Schnell U, Kuipers J, Giepmans BN. EpCAM proteolysis: new fragments with distinct functions? Biosci Rep 2013; 33: e00030. 